\title{
Fall risk factors in community-dwelling elderly people
}

\author{
Astrid Bergland \\ Oslo and Akershus University College of Applied Sciences, Faculty of Health Sciences, Postboks 4, \\ St. Olavs plass, $\mathrm{N}-0130$ Oslo, Norway \\ E-mail: astrid.bergland@hioa.no Telephone:+4722452507
}

\begin{abstract}
Falls are a common and serious problem for older adults. Approximately one-third of older communitydwelling people fall at least once a year. The main purpose of this paper is to present risk factors for fall in older people living at home. The databases used for identifying documentation of risk factors are Cinahl, Eric, ISI Web of Science, Cochrane Medline, Psycinfo and dissertation. Many psychosocial and medical conditions and impairment of sensorimotor function, balance and gait have been shown in large epidemiological studies to be strongly associated with falls. Several of the risk factors are interrelated. The intrinsic-extrinsic distinction seem to be an oversimplification. A better understanding of falls is usually obtained when examining the person in association with the environmental factors. Advanced age, history of falls, ADL limitations, impaired gait and mobility, visual impairment, reduced sensation, muscular weakness, poor reaction time, impaired cognition, diseases as stroke, use of psychoactive medication and use of many medications are risk factors shown to be strongly associated with falls. This means recommendation of multifactorial fall risk assessment must incorporate a range of physiological and mental tests in addition to assessing balance and gait as well as taking multiple chronic diseases and medications into account. These finding underscore the importance of multidimensional fall intervention with special focus on modifiable risk factors.
\end{abstract}

\section{INTRODUCTION}

Population ageing and the increased tendency to fall with age, present a major challenge to health care providers and health systems as well as for older people and their carers. Each year approximately one-third of older people fall, and the chance of falling increase with age (1-6). Despite decades of research on fall prevention, falls among older adults impose substantial personal and societal burden $(2,7,8)$. Prevention and management of falls in older people has become a key public health priority in many westernised countries (2,9-14) because falling cause considerable disability, loss of independence and premature mortality $(15,16)$. $\mathrm{An}$ indicator of the importance of focusing on falling was the existence of 'Prevention of Falls Network Europe' (ProFaNe). ProFaNe is funded by the European Commission to consolidate and disseminate good practice in taxonomy and clinical trial methodology as well as detailed clinical assessment and management protocols for those 'at risk' of falls (www.profane.org.uk). In order to more fully understand consequences of falls, methods to reduce fear of falling and how to increase adherence to falls prevention intervention, ProFaNE also aims to identify how best to assess balance function and the role of psychological factors as risk factors for falls (17-19). A fall suffered by an older person can have severe personal consequences and important implications for health care. The relative ageing of populations in developed countries is likely to see the costs associated with falls increase dramatically over the next 20 years (20).

The conclusion of Beard et al. (20) was that a welldesigned community-based intervention, targeting falls prevention among older people, are highly cost effec- tive and a wise investment for all levels of government. The strength of evidence that falls in later life can be prevented has grown to the point where it can no longer be ignored by health policy makers and providers $(1,21-24)$. Falls and their consequences can be prevented, for example by identifying and treating the reason(s) for falling. Fall prevention is of a multidisciplinary nature $(1,15)$. Falls are a common and potentially modifiable cause of morbidity among older people. After several decades of research on intervention to reduce falls and injuries, we have evidence for a number of fall prevention approaches, supported by systematic reviews and meta-analyses (i.e. 1,11,23,2532). Rose and Hernandez (33) concluded that depending on the level or risk identified, physical activity or exercise may serve a primary, secondary, or tertiary role in the prevention of fall.

A first step in the majority of effective programs may involve identifying individuals at increased risk of falls $(17,1)$. Knowledge of fall demographics and risk assessment is important to help health professionals and their users with formulate falls prevention and target those at highest risk. Therefore the main purpose of this paper is to present risk factors for fall in older people living at home. One would think that the rational approach to the prevention of falls would be the identification of risk factors and the appropriate targeting of intervention. The main target audience of this paper is potential partners for falls prevention which may include:

- Individuals and organizations representing older persons at risk of falling

- Health and sosial service providers

- Emergency service providers

- Researchers and educators 


\section{LITERATURE REVIEW}

From the 1960ies, when Sheldon described the literature on falling as "meagre" (34), there has been a marked growth in research (35). Therefore we suggest that the literature now is too vast for any individual researcher to fully assimilate. Hence this paper is selective and the review method used is the 'traditional review' which aims to present the current state of knowledge about a particular subject (36), in this case risk factors for falling. Furthermore, the 'traditional review' also seeks to add new insights on the topic. According to Jesson et al. (36) the traditional review is implicit based on reviews the author's subjectivity; there is no protocol except for some description of the choice made on selection (ibid). The author is a researcher on fall prevention. The review included literature on evidenced-based risk-factors. The databases used are Cinahl, Eric, ISI Web of Science, Cochrane Medline, Psycinfo and dissertation. In short, a combination of different variations of the following text words was used: accidental fall and risk factor. We used the two following inclusion criteria: home-dwelling adult aged 65 or older and articles should be published in English. This paper describes the risk factors for falls in line with Lord et al. (35) who are dividing risk factors into sociodemographic factors, balance and mobility factors, sensory and neuromuscular factors, psychological factors, medical factors, medication use, and environmental factors. Hauer et al. (12) state that it appears to be variations in the methods of identifying when a fall has occurred, in the details recorded, and in the methods of analysis. The ProFaNE collaborators, in conjunction with international experts in the field, have adopted a definition which includes falls that occur from all causes, i.e. an unexpected event in which the participant comes to rest on the ground, floor or lower level (37). Without standardisation of falls definitions, we will not be able to extract useful data for clinical guidelines on fall prevention intervention (38). Falls are coded as E880-E888 in International Classification of Disease-9 (ICD-9), and as W00-W19 in ICD-10. These codes include a wide range of falls, including falls without specifications.

\section{RISK FACTORS FOR FALLS}

Identifying risk factors is an important first step in maintaining optimal function and preventing falls (39). The term "risk" relates to the probability that an event, generally an unfavourable one, will occur within a stated period of time or before a stated age. A risk factor may be an aspect of personal behaviour or life-style, an environmental circumstance, or an innate or inherited characteristic which on the basis of epidemiological evidence is known to be associated with some healthrelated condition(s) considered important to prevent (40). This is not necessarily a causal factor but is a marker of increased probability. Harwood (41) focused on the importance of realising that falls risk is a continuum, in the meaning that what varies, is the probability that an individual will fall during a given activity or external insult. Much of the variation in the risk of falling is due to biological and functional variability within age groups, rather than to simple age-dependent variations (42). Falls are almost always caused by many interacting factors, usually a combination of intrinsic and extrinsic ones (35,43-47). Intrinsic factors are individual-specific and include age, chronic disease, muscle weakness, gait and balance disorder, and cognitive impairment. Extrinsic factors generally include medication use, environmental hazards, and hazardous activity (5). Falling generally results from an interaction of multiple and diverse risk factors and situations such as physical, musculoskeletal and psychosocial $(35,48-50)$. Several studies have shown that the risk of falling increases dramatically as the number of risk factors increases (34,51-56). Delbaere et al. (57) stated that the absolute risk for falls ranged from $11 \%$ in those with no risk factors to $54 \%$ in the highest risk group which consists of people with high physiological fall risk score, impaired executive functioning, and poor dynamic balance and who did not participate in any regular planned exercise had the highest fall risk (absolute risk $54.4 \%$ ). The multifactorial nature of falls cannot be overemphasized $(35,58,59)$.

\section{Sociodemographic factors as risk of falling}

The risk of falls increases after the age of $60(5,60)$, and several studies have found age to be a significant predictor of falling as well as previous fall $(5,34,52,58,61$ $66)$. It is well established that $30 \%$ of people over the age 65 years living in the community, fall each year $(48,49,52,67-75)$. The frequency is over $40 \%$ for those over 75 years $(67,68)$ and almost one in two persons over 80 years of age will fall at least once each year $(49,52,68,76)$. Fall-related injuries increase markedly with age $(77,78)$. A history of falls seems to be a marker of frailty, poor mobility, and acute or chronic health impairment. The mere fact of having suffered a previous fall reveals little about the cause of the falls. Among others, Lord et al. (35), O'Loughlin et al. (49), Luukinen et al. (78), Brauer et al. (79), Tromp et al. (80), Flemming (81), Andresen et al. (82), Covinsky et al. (83) and Tsai et al. (84) found that subjects with a fall history are more likely to sustain further falls. In a metaanalysis of six prospective studies of falls in patients with Parkinson's disease, Pickering et al. (85) concluded that the strongest predictor was falls in the preceding year.

Studies of community samples reveal a lack of agreement on the association between falls and gender. Some authors suggest that women are more likely to fall than men $(1,5,67,75,78,86,87)$, while others have found no gender differences in the rate of falling (63, $68,74,88-91)$. Other studies omit an analysis by gender because they have a predominantly $(62,92)$ or entirely female sample (49,93-95). 


\section{Impairments}

Impairments are problems in body function or structure, i.e. a significant deviation from what is considered the norm. The definition is undertaken primarily by those qualified to judge physical and mental functioning according to a generally accepted population standards (96). It does not matter how the impairment occurred; for example, loss of vision or a limb may arise from a genetic abnormality, a disease or an injury. Impairments are categorised using defined criteria (for example, as present or absent at a predefined level) (96). Greater loss of sensory function has been observed in the lower extremities in fallers (97). Furthermore, reduced peripheral sensation or proprioception is known to be associated with falls $(49,98-107)$, for instance loss of sense of vibration $(49,105-109)$ or tactile sensitivity $(49,100,110)$. Anacker et al. (111) reported that older fallers tend to be more dependent on somatosensory cues from the feet and ankles than nonfallers. Vestibular impairment may contribute to falls and fall-related fractures in older people (1,112-115). Lord et al. (35) reported epidemiological data that showed that multifocal spectacle users are more than twice as likely to fall as non-multifocal spectacle users, and that this risk was increased during stair negotiation. This greater risk was attributed to impaired contrast sensitivity and depth perception at critical distances for environmental hazard (ibid).

Many authors have reported that visual impairment, including sensitivity to contrast $(35,80,95,99,116-121)$, inability to adapt to the dark $(121,122)$, poor depth perception $(34,120,121)$, poor visual acuity $(61,94$, $117,119-121,123)$, self-reported poor vision $(89,124)$ and visual field impairment $(117,121,124,125)$, were significantly associated with falls. From the point of view of assessing risk of falls Harwood (41) suggests that the main functions are visual acuity, contrast sensitivity and depth perception and concluded that these functions are generally quite closely correlated. Campbell et al. (48) found a significant association between lack of visual acuity and falls in a fairly large sample of older people living in the community, but this association disappeared when adjusting for age. However, contrast sensitivity is more important than visual acuity in predicting falls $(98,117,126)$. Many studies have identified lower-extremity weakness as a risk factor of falls $(34,48,52,62,68,98,99,127,128)$ as well as grip strength $(129,130)$. DeMott et al. (131) showed that older persons with peripheral neuropathy have a high rate of falls.

\section{Somatic disorders}

Number of chronic conditions or diseases, are significantly associated with future fall $(5,35,93)$. Frail, elderly people with more than one chronic illness experience higher rates of falls than active healthy older people $(35,49,54)$. Neurological problems like stroke, Parkinson's disease, cerebellar dysfunction, vestibular pathology are all related to falls $(5,34,35,48,62,67,107$, 132-134). Beninato et al. (132) state that falls following stroke are disturbing frequently, with reported fall rates ranging from $22 \%$ to $73 \%$ in community-dwelling people with stroke. Regarding examining risk factors in patients with several diseases an important question is whether risk factors in one disease group are relevant risk factors in other patient groups or healthy elderly as well. Example of comparison of older adults with and without stroke is described in a recently publicized study of Simpson et al. (135) of a sample of 80 people with stroke and 90 controls who all received baseline assessments of balance, mobility and balance confidence. Falls were recorded prospectively over 13 months for both groups. The rate of falls for individuals with stroke was 1.77 times the rate for the control group. Poorer balance (Berg Balance Scale) was associated with greater falls for both stroke and control groups (incidence rate ratio [IRR]: 0.908 and IRR: 0.877 respectively). A faster Timed Up and Go Test was associated with greater falls for the stroke group (IRR: 0.955) while better walking endurance (Six Minute Walk Test) was associated with greater falls for the controls (IRR: 1.004). Balance confidence was not an independent predictor in either group. Furthermore Schmid et al. (136) found in their post stroke population that fall risk is common, with half of the patients being at risk of falls. Additionally, they found that an increased stroke severity evaluated using the "The National Institutes of Health Stroke Scale" (NIHSS). NIHSS is independently associated with a greater prevalence of fall risk. They concluded that given that stroke severity is a characteristic easily measured in routine clinical practice, it may be a useful tool to identify stroke patients who would benefit from a comprehensive fall risk assessment. Furthermore, cardiovascular problems i.e. orthostatic hypotension, has been suggested as a risk factor for falling $(128,137)$, but Liu et al. (91) could not confirm this.

Lower extremity problems, such as osteoarthritis have been found to be a significant risk factor for falling in several prospective studies $(34,10,48,68)$. In addition, symptoms like pain and a reduced range of motion in the knees and hips (48) were associated with an increased risk of falling. One prospective study reported that older people with severe bunion, toe deformity, ulcer and deformed nails have a two-fold increased risk of falling (52). Foot problems are generally poorly defined, making it difficult to delineate the contribution made by specific foot conditions to falls. Menz and Lord (138) studied foot problems and concluded that they are common in older people and may contribute to functional impairment and falls in the older group. In a systematic review Moreland et al. (139) reported that persons with lower extremity weakness, usually measured by knee extension, ankle dorsiflexion and the test "chair stands", have a 1.8-fold increased risk of falling and 3-fold risk for recurrent falls. 


\section{Cognitive and emotional health condition}

The role of mental factors as risk factors for falls, have received less attention than that of physical health. However, cognitive impairments have been identified as risk factors in several studies $(34,48,52,61,62,67$, $128,140)$. Wright et al. (140) state that cognitive factors are increasingly recognized as contributing to a fall risk in older adults and that executive dysfunction has been found to be the primary cognitive domain that predicts falls, with other cognitive skills, such as memory, being less related to falling. Community studies of falls have generally excluded cognitively impaired individuals $(68,70,93)$, mostly because cognitive impairment can preclude the reporting of falls and thus the identification of risk factors. A decline in cognition may well be an important factor in predisposing a person to fall $(35,141,142)$. The exclusion of such persons with a potentially higher risk, probably results in an underestimate of the risk of falling.

Attentional resources have been identified as an important factor related to the risk of falling (143-147). Woolley et al. (148) indicate that the disturbances in components of balance like selective attention, perceptual style and reaction time, are associated with falls. Holtzer et al. (149) reported associations between reduction in cognitive functions and falls.

It has for long been known that depression and anxiety are associated with falls in the elderly $(34,80,87$, 91,140). Arfken et al. (150) and Lord et al. (35) concluded that persons most afraid of falling do suffer more falls.

\section{Medication}

Medication as a risk factor for falls has been critically evaluated in structured meta-analyses $(151,152)$. Although multiple drug use may be viewed as an indicator of poor health, there is increasing evidence that polypharmacy may lead to falls as a result of adverse reactions to one or more medications, detrimental drug interaction, and/or incorrect use $(5,35,48,52,66,68,90$, $93,128,153,154)$. While the association between polypharmacy and falls is well established, the relationship between specific classes of drugs and the risk of falling is less clear. Leipzig et al. (151) found in their meta-analyses a significant association between falls and use of neuroleptics, sedative/hypnotics and any antidepressant. For the benzodiazepine drugs, there was a difference between short- and long-acting substances. Regarding cardiac and analgesic drugs, Leipzig et al. (152) made an overview of twenty-nine studies. For one or more falls, the pooled odds ratio was statistically significant for diuretics, nitrates, type Ia antiarrhythmic and digoxin. Older adults taking more than three or four medications were also at increased risk of falls $(151,152)$. Hartikainen et al. (155) concluded in their systematic review article that the main group of drugs associated with an increased risk of falling was psychotropics; benzodiazepines, antidepressants, and antipsychotics. Antiepileptics and drugs that lower blood pressure were weakly associated with falls. French et al. (156) concluded that in their study, subjects with a health care encounter for a fall (as indicated by diagnostic code) were prescribed significantly more CNS-category medications than subjects in the age- and sex-matched comparison group.

\section{Activity and participation}

Activity is the performance of a task or action by an individual (96). The activity dimension consists of simple and more complex tasks (such as walking, obtaining food and performing tasks simultaneously). Falls are often related to changes in how an individual uses the environment (for example, the faller was hurrying or inattentive) or to difficulties or discomfort experienced when using the environment. Prospective studies evaluating the association of usual physical activity with the risk of falling have given equivocal results, but seem to suggest a U-shaped association, where the most inactive and the most active people are at highest risk $(34,49,52,100,157)$. However, how to measure the level of physical activity, represent a big challenge. A systematic literature review by JørstadStein et al. (158) aimed at identifying and appraising physical activity questionnaires that could potentially be used in clinical trials of fall-injury prevention among older adults. They found no entirely satisfactory measures. Chan et al. (129) showed in a large prospective cohort study of 5,995 community dwelling men, at least 65 years of age, that the most active quartile had a significant greater fall risk than did the least active quartile.

Inability to perform the basic activities of daily living (ADL) and self-reported limitations in mobility, are generally associated with a doubled or tripled risk of falling (35). Frail elderly people tend to fall while carrying out ADL (54). Lord et al. (35) state that $44 \%$ of the falls occurs at various locations in the home (26\% while walking on a level surface, $6 \%$ while using the shower or bath, $9 \%$ on stairs and $3 \%$ relates to chair/ladder), the rest outside the home. Information about what the persons were doing and the activity level when falling seems crucial for understanding the aetiology of falls as well as for effective clinical assessment and the development of preventive strategies.

Studies have shown that $30-70 \%$ of older adults' falls are due to trips, slips, and stumbles during walking $(52,67,93,124)$. Thus, walking is the main activity in which the majority of falls among older adults living in the community occurs.

Social isolation may result in unintentional or possibly intentional falls as a way to gain attention or end one's life (159). Even in apparently healthy older individuals engaged in commonplace activities, the risk of falling is substantial, suggesting that psychosocial, situational and behavioural factors are significant causes of falls $(80,160)$. The social environment, such as living situation showed that single persons, living alone reported falls at a higher rate than those who lived with others $(5,161,162)$. 


\section{Environment of falling}

Fall risk is complicated to assess, and the exact role of environmental factors is not known (163). Nevertheless, the variety of places where individuals fall, as well as countless other factors which has been identified as fall risks, suggest that the role of the environment is interactive with other intrinsic, extrinsic, and behavioural risk factors (ibid). Behavioral fall risk factors are those that reflect choices of older individuals with respect to how they interact within their environments. Examples of behavioural risk factors include performing behaviours that increase fall risk e.g. standing on unstable objects to reach items that are stored on high shelves); not performing behaviors that could reduce fall risk (eg, failing to turn on lights when using the bathroom at night or not using grap bars or handrails when they are present); or selecting unsafe clothing, footwear, or inappropriate or outdated eyewears prescriptions. Some researchers have reported that the frequency of outdoor falls was higher compared with indoors falls $(18,88,93,164-166)$. The external/internal distinction is not clear-cut, for example, a rug on a highly polished floor may cause an infirm woman to fall while a more able woman could have saved herself (167). Nevitt et al. (34) reported that environmental factors (stairs or tripping and slipping hazards) were associated with $61 \%$ of falls that occurred away from home and $33 \%$ of those that occurred at home. A high proportion of falls occurs on steps and stairs $(52,93)$. With increasing age, falls occur more frequently inside the home on level surface (35). Bath and Morgan (164) found that people aged 75 or less were more likely to fall outdoors than people aged 75 and over. Women seem more likely to fall within their usual residence, while men tend to fall in their own gardens (63). According to Speechley and Tinetti (54) $20 \%$ tend to fall while away from home. Commonly reported environmental factors leading to falls in public places include pavement cracks and misalignments, gutters, steps, construction works, uneven ground and slippery surfaces (35).

Some authors report that environmental hazards are more likely to contribute to falls in elderly people in better health than in those of their more frail counterparts $(35,47,93,165)$. In a study of over 1,400 people living in the community, Weinberg and Strain (165) found that those with better self-rated health were more likely to attribute the cause of a fall to the surroundings outdoors. Bath and Morgan (164) found in an eight-year post-fall monitoring period that multiple $(3+)$ fallers and indoor fallers showed a significant excess mortality. Those with poorer self-rated health and those who reported having dexterity difficulties were more likely to attribute their falls to their own limitations. Studenski et al. (168) found that those at low risk of falling (immobile, or mobile and stable) were either more able to withstand environmental challenges or were not as challenged by their environments as the high-risk (mobile and unstable) people.
Dresner-Pollak et al. (169) found that falls mainly occurred outside the home and suggested that these people were active and spent a longer period of their day outdoors, where the risk of a fall was higher.

\section{Balance and gait as predictors of falling}

Balance and gait are predictors of falling $(35,121,170)$. Lord et al. (35) summarised the results of various measures of postural stability and their relationship with falls, and showed that the risk of falling increases with more challenging stability tasks. Lord et al. (35) concluded that reduced gait velocity, cadence and step length were strongly associated with risk of falling. Generally speaking, the more challenging the balance task the stronger its association with falls (171). There are a substantial number of balance fall-risk screening tools described in the literature $(170,172-176)$. The AGS/BG guideline (174), recommend the Timed Up and Go Test (TUG) as a screening tool for identifying older people at increased risk of falls. Perell et al. (175) and Scout (170) have examined the predictive validity of functional mobility assessment tools for predicting falls among older adults in the community. They concluded that, in addition to TUG, the Tinetti's Performance-Oriented Mobility Assessment, the Berg Balance Scale, the Modified Gait Abnormality Rating Scale and the Elderly Fall Screening Test, Functional Reach, 5 minute walk, Five-Step Test were useful tests.

Lajoie and Gallagher (176) showed that a cut-off at 46 on Berg-Balance Scale was statistically effective in predicting falls in the elderly community. A sensitivity and specificity of correctly classifying fallers and nonfallers with a cut-off of 46 is $82.5 \%$ and $93 \%$, respectively. A score of $67 \%$ on Activities-specific Balance Confidence was a reliable means of predicting a future fall. In fact, this score was highly specific and sensitive with values of $87.5 \%$ and $84 \%$, respectively (ibid).

Stel et al. (130) concluded that the easy measurable Tandem Stand predicted recurrent falling. Jarnlo (177) concluded that the best predictor of future falls was Berg Balance Scale in combination with self-reported imbalance. In a recent systematic review Neuls et al. (178) concluded that Berg Balance Scale alone was not useful for predicting falls in older adults with and without pathological conditions. Given the varied recommended cutoff scores and psychometric values, clinicians should use Berg Balance Scale in conjunction with other test/measures considering unique patient factors to quantify the chances of fall in the older adults.

Gait performance in older adults has been shown to relate to risk of falling $(35,49,93,121,127,148,179$ 182). In a review of the literature, Piirtola and Era (183) have highlighted the small number of prospective studies evaluating the association between balance measurement by posturography and the risk of fall, and the conflicting results of these studies. Posturography makes use of a forceplate to measure the motion of the person's centre of pressure at ground level. They con- 
cluded that certain aspects of force platform data may have predictive value for subsequent falls, especially various indicators of the lateral control of posture. However, the small number of studies available makes it difficult to draw definitive conclusions. Furthermore, Buatois (184) concluded that bad performance on posturography evaluation under conflicting sensory conditions, by the Sensory Organization Test, appear to be a sensitive tool to identify people at high risk of recurrent falls. Prospective studies have revealed that an individual's sway is a useful predictor of the risk of falling $(62,86,93,98,99,110,120,145)$. Hale et al. (185) stated that one explanation for the association between mobility score and falls is that more mobile elderly persons are exposed to greater environmental and other activity-related risks of falling. Less mobile people may be more cautious and less active, and thus limit their risk of falling (186).

\section{METHODOLOGICAL ISSUES IN THE LITERATURE}

A number of methodological issues occur in the studies examined in this review, many of which limit interpretation of the findings of risk factors of fall. Studies of falls suffered by people living in the community can be divided into population surveillance studies and surveys of elderly people living at home (43). Population surveillance studies usually involve the analysis of the medical records of fallers who receive medical treatment at an accident and emergency department (43). Community surveys collect information on both fallers and non-fallers, allowing risk factor identification (43). Each type has advantages and disadvantages in terms of accuracy, cost and generalizability. Comparison of results across studies is made difficult by differences between studies regarding the age of those included, the fall definition used, the classification of the resulting injury and differences in methodology.

Another methodological issue is the sample included in the study. Ideally, the whole population should be studied, but the logistics of this kind of study are difficult. It is more realistic and manageable to select a representative sample. Any group of the elderly will be a mixture of people with different intrinsic risks of falling, different environments and different lifestyles which together will define them at high, intermediate or low risk of falling. Although most community surveys tend to be based on large samples (for example, over 700 people), a number of studies of falls have employed small and often highly selected, sometimes non-random, samples $(34,122,143,186)$. One problem that results from small sample sizes is low statistical power, which leads to important differences being undetected.

The selection criteria used in the sampling process must not be ignored when reviewing studies. Nevitt et al. (34) and Campbell and colleagues (48) excluded those unable to walk unassisted, and those unable to answer an interviewer's questions, whereas Cumming and Klineberg (51) excluded subjects with cognitive impairment. There is evidence suggesting that subjects with cognitive impairment are more likely to fall, i.e those who are most at risk of falling may be least likely to remember their falls (35). Hill et al. (186) excluded those with a history of falls in the 12 months prior to the start of the study and those with medical problems which might affect balance or mobility. Clearly, where important subgroups have been excluded, it is impossible to generalise to the whole population.

Still another methodological issues regarding risk factor for fall is use of retrospective or prospective design (186). Both case-control and cross-sectional studies may be used to examine risk factors, though retrospective designs are much weaker (187). Such studies have been criticised for their lack of reliability and validity $(35,39,116)$. In cross-sectional studies, one has to face the problem of being unable to discriminate between a cause and the effect of a relationship between two or more variables. It may be difficult to determine whether the cause or effect came first. Casecontrol designs have been shown to yield optimistic results for the evaluation of diagnostic tests, a result that is likely to be relevant to prognostic studies (188). In a retrospective cohort design, samples representing persons with and without a history of fall, in a defined period of time, are compared to identify the risks of falling. Retrospective designs are weaker than prospective designs in identifying people at risk of future falls, because information on risk factors and falls is susceptible to recall bias, and also because the presence of a risk factor is not identified before the occurrence of a fall. Because falls may be forgotten, denied or explained as being normal in the surrounding circumstances, it is most likely that the reported number of falls is too low, especially in retrospective studies. Most retrospective studies find that $30 \%$ of older persons experience one or more falls each year $(35$, 67). A number of methods have been used to record falls in prospective follow-up periods. These include monthly or bi-monthly mail-out questionnaires $(35,95$, 99), weekly (34), or monthly falls calendars (52) and monthly telephone interviews (67). Prospective fall studies are more reliable because of their potential for greater data precision regarding the major outcome, falls. Their major disadvantage is the time and expenses associated with a long period of data collection. Studies with a prospective design usually find a higher rate of falls (35). In the studies by Hill et al. (186) the annual rate of falls was $49 \%$, and still higher (61\%) in the study by Maki et al. (62).

Reliable methods for detecting falls are extremely relevant in two aspect; firstly, in order to signal the occurrence of a fall so that suitable measure can be initiated when assistance is needed (i.e. fall alarms), and secondly, to obtain valid documentation of falls (falls reports). At present, there is no unanimous accepted method for reporting falls. The ProFaNE collaborators 
recommended that falls should be recorded using prospective daily recording and a notification system with a minimum of monthly reporting (37). Telephone or face to face interview should be used to chase missing data and to ascertain further details of falls and injuries. Specific information about the circumstances of any fall can also be ascertained with additional questions on the falls diary forms. In research studies, fall data should be summarized as: number of falls, number of fallers/non-fallers/frequent fallers; and fall rate per person years (37). Hauer et al. (12) refer to the following three systems of prospective reporting; calendar, diary and postcard. The accuracy of each reporting system is difficult to determine (185).

Regarding the outcome of research into falls most studies report the number of subjects who experience one or more falls over the study period, rather than the incidence rate of falls (35). An examination of the fall literature revealed a general lack of agreement in the ways in which falls are defined and classified. Campbell and colleagues (61) distinguished between a "pattern fall" and "occasional falls". In two retrospective studies, Bath and Morgan (164) and Bergland et al. (93) used the categories outdoor fall and indoor fall which is also used in prospective studies. Whereas some studies have concentrated on falls in general, others have considered only "injurious falls" (53). Yet others investigated multiple or recurrent fallers (80). For better comparability of study results Hauer et al. (12) recommended a core set of fall outcome measures, including number of falls, fallers, fall rate and time of first fall, to summarise fall data. There is limited comparability between studies due to the different focus on risk factors, and different classification of risk factors investigated in each of these studies. In addition, individuals with multiple risk factors have an increased rate of falls compared to individuals with one risk factor (35,52). Moylan and Binder (58) stated that the multifactorial nature of falls cannot be overemphasized. Another distinction concerns the follow-up time. Most studies have a one-year follow-up (35), but Brauer et al. (79) have a six months follow-up period.

\section{CONCLUSION AND RECOMMENDATION FOR PRACTICE}

The results of this literature review could provide a valuable resource for those involved in fall prevention. Falls are multifactorial in origin. History of falling, advanced age, balance and mobility limitation, poor visual, impaired cognition, diseases as stroke, Parkinson and use of multiple medications are all factors strongly associated with increased risk of falls.

This means that all older persons should be asked whether they have fallen in the past year. A further strategy to reduce the risk of falls should include multifactorial assessment of known fall risk factors and management of the risk factors identified. Those who report a single fall might be evaluated for gait and balance and those who proved to be unsteady during the evaluation of gait and balance might have a multifactorial fall risk assessment which includes a focused history of fall as well as physical examination, functional assessment and environment assessment.

The finding of this paper underscores the importance of multidimensional fall intervention with special focus on modifiable risk factors are of importance for fall intervention. Two important components most commonly included in efficacious fall prevention interventions were: a) Exercise, particularly balance, strength, and gait training, and b) Adaptation or modification of home environment. Furthermore, withdrawal or minimization of psychoactive medications and withdrawal or minimization of other medications.

\section{REFERENCES}

1. Gillespie LD, Gillespie WJ, Cumming R, Lamb SE, Rowe BH. Interventions for preventing fall in the elderly. Cochrane Database Syst Rev 2009; 4:doi:10.1002/14651858.CD000340.

2. World Health Organization. WHO Global report on falls prevention in older age. Geneva: World Health Organization, 2007.

3. Harholt K, van Beeck EF, Polinder S, van der Velde V, van Lieshout EMM, Panneman MJM, et al. Societal consequences on falls in the older population: Injuries, healthcare costs, and long-term reduced quality of life. J Trauma 2011; 71: 748-753.

4. Page P. Standing Strong: Bringing Evidence to Practice for a Community-Based Fall Prevention Exercise Program. Top Geriatr Rehabil 2010; 26 (4), 335-352.

5. Deandrea S, Lucenteforte E, Bravi F, Foschi R, La Vecchia C, Negri E. Risk factors for falls in communitydwelling older people: a systematic review and meta-analysis. Epidemiology 2010; 21: 658-68.

6. Tiedemann A, Sherrington C, Close JC, Lord SR. Exercise and Sports Science Australia position statement on exercise and falls prevention in older people. J Sci Med Sport 2011; 14: 489-495.

7. Fixsen D, Scott V, Blasé K, Naoom S, Wagar L. When evidence is not enough: the challenge of implementing fall prevention strategies. J Safety Res 2011; 42: 419-22.

8. Keller MJ. A holistic approach to developing fall-prevention programs for community-dwelling older adults. Activities, Adaptation \& Ageing 2009; 33: 223-239.

9. Watson W, Clapperton A, Mitchell R. The burden of fall-related injury among older persons in New South Wales. Aust N Z J Public Health 2011; 35:170-175. 
10. Chan BKS, Marshall LM, Winters KM, Faulkner KA, Schwartz AV, Orwoll ES. Incident fall risk and physical activity and physical performance among older men. Am J Epidemiol 2006; 165: 696-703.

11. Salter AE, Khan KM, Donaldson MG, Davis JC, Buchanan J, Abu-Laban RB, et al. Community-dwelling seniors who present to the emergency department with a fall do not receive guideline care and their fall risk profile worsens significantly: a 6-month prospective study. Osteoporos Int 2006; 17: 672-683.

12. Hauer K, Lamb SE, Jorstad EC, Todd C, Becker C. Systematic review of definitions and methods of measuring falls in randomised controlled fall prevention. Age Ageing 2006; 35: 5-10.

13. Johnson SJ. Frequency and nature of falls among older women in India. Asia Pac J Public Health 2006; 18: 56-61.

14. Yardley L, Donovan-Hall M, Francis K, Todd C. Older people's views of advice about falls prevention: a qualitative study. Health Educ Res Theory Prac 2006; 21: 508-517.

15. Rubenstein LZ, Vivrette R, Harker JO, Stevens JA, Kramer BJ. Validating an evidence-based, self-rated fall risk questionnaire (FRQ) for older adults. J Safety Res 2011; 42: 493-499.

16. Sylliaas H, Idland G, Sandvik L, Forsen L, Bergland A. Does mortality of the aged increase with the number of falls? Results from a nine-year follow-up study. Eur J Epidemiol 2009; 24: 351-355.

17. Skelton DA, Todd CJ, on behalf of the ProFaNE Group. Thoughts on effective falls prevention intervention on a population basis. Public Health 2004; 13: 196-202.

18. Skelton DA, Becker C, Lamb SE, Close JCT, Zijlstra W, Yardley L, et al. Prevention of Falls Network Europe: a thematic network aimed at introducing good practice in effective falls prevention across Europe. Eur J Aging 2004; 1: 89-94.

19. Skelton DA, Todd CJ. On behalf of the ProFaNE group. Prevention of falls Nettwork Europe: a thematic network aimed at introducing good practive in effective falls prevention across Europe. Four years on. $J$ Musculoskeletal Neuronal Interact 2007; 7: 273-278.

20. Beard J, Rowell D, Scott D, Van Beurden E, Barnett L, Hughes K, Newman B. Economic analysis of a community-based falls prevention program. Public Health 2006; 120: 742-751.

21. Swift CG. The role of medical assessment and intervention in the prevention of falls. Age Ageing 2006; 35: 65-68.

22. Chang JT, Morton SC, Rubenstein LZ, Mojica WA, Maglione M, Suttorp MJ, et al. Intervention for the prevention of falls in older adults: systematic review and meta-analysis of randomized clinical trials. $B M J$ 2004; 318: 680-683.

23. Gates S, Lamb SE, Fisher JD, Cooke MW, Carter YH. Multifactorial assessment and targeted intervention for preventing falls and injuries among older people in community and emergency care settings: systematic review and meta-analysis. BMJ 2008; 336: 130-133.

24. Feder G, Cryer C, Donovan S, Carter Y. Guidelines for the prevention of falls in people over 65. BMJ 2000; 321: 1007-1011.

25. Clemson L, Mackenzie L, Ballinger C, Close JCT, Cumming RG. Environmental interventions to prevent falls in community-dwelling older people: a meta-analysis of randomized trials. Aging Health 2008; 20: 954-71.

26. Gardner M, Robertson M, Campbell A. Exercise in preventing falls and fall related injuries in older people: A review of randomized controlled trials. Br J Sports Med 2000; 34: 7-17.

27. Sherrington C, Whitney JC, Lord SR, Herbert RD, Cumming RG, Close JCT. Effective exercise for the prevention of falls: a systematic review and meta-analysis. J Am Geriatr Soc 2008; 56: 2234-2243.

28. Petridou ET, MantiEG, Ntinapogias AG, Negri E, Szczerbinska K. What works better for communitydwelling older people at risk to fall? A meta-analysis of multifactorial versus physical exercise-alone interventions. Aging Health 2009; 21: 713-29.

29. Arnold CM, Sran MM, Harrison EL Exercise for fall risk reduction in community-dwelling older adults: a systematic review. Physiother Canada 2008; 60: 358-72.

30. Bunn F, Barnet-Page E, McInnes E, Dickinson A, Horton K. A systematic review of older people's perception of facilitators and barriers to participation in falls-prevention interventions. Ageing Soc 2008; 28: 448-72.

31. Logghe IH, Verhagen AP, Rademaker AC, Bierma-Zeinstra SM, van Rossum E, et al. The effects of Tai Chi on fall prevention, fear of falling and balance in older people: A meta-analysis. Prev Med 2010; 51: $222-227$.

32. Davis JC, Robertson MC, Ashe MC, Liu-Ambrose T, Khan KM, Marra CA. Does a home-based strength and balance programme in people aged $\geq 80$ years provide the best value for money to prevent falls? A systematic review of economic evaluations of falls prevention interventions. Br J Sports Med 2010; 44: 80-89.

33. Rose DJ, Hernandez D. The role of exercise in fall prevention for older adults. Clin Geriatr Med 2010; 26: 607-631.

34. Nevitt MC, Cummings SR, Kidd S, Black D. Risk factors for recurrent nonsyncopal falls. A prospective study. JAMA 1989; 261: 2663-2668.

35. Lord SR, Sherrington C, Menz HB, Close J. Falls in Older People. Risk Factor and Strategies for Prevention. Cambridge: Cambridge University Press, 2007. 
36. Jesson JK, Matheson L, Lacey FM. Doing your literature review: traditional and systematic techniques. Sage Los Angeles, 2011.

37. Lamb SE, Jørstad EC, Hauer K, Becker C. Prevention of Falls Network Europe and Outcome Consensus Group. Development of a common outcome data set for fall injury prevention trials: the Prevention of Falls Network Europe consensus. J Am Geriatr Soc 2005; 53: 1618-1622.

37. National Institute of Clinical Excellence. Clinical practice guideline for the assessment and prevention of falls in older people 2004; www.nice.org.uk/page.aspx?o=2011.

39. Belgen B, Beninato M, Sullivan PE, Narielwalla K. The association of balance capacity and falls self-efficacy with history of falling in community-dwelling people with chronic stroke. Arch Phys Med Rehabil 2006; 87: 554-561.

40. Last JM. A Dictionary of Epidemiology. New York: Oxford University Press, 2001.

41. Harwood RH. Visual problems and falls. Age Ageing 2001; 30 (Suppl 4): 13-18.

42. Radebaugh TS, Hadeley E, Suzman R. Falls in the elderly: biologic and behavioral aspects. Clin Geriatr Med 1985; 1: 555-620.

43. Lilley JM, Arie T, Chilvers CE. Accidents involving older people: a review of the literature. Age Ageing 1995; 24: 346-365.

44. Campbell AJ. Drug treatment as a cause of falls in old age. A review of the offending agents. Drugs Aging 1991; 1: 289-302.

45. Hornbrook MC, Stevens VJ, Wingfield DJ, Hollis JF, Greenlick MR, Ory MG. Preventing falls among community-dwelling older persons: results from a randomized trial. Gerontologist 1994; 34: 16-23.

46. King MB, Tinetti ME. Falls in community-dwelling older persons. J Am Geriatr Soc 1995; 43: 1146-1154.

47. Bath PA, Pendleton N, Morgan K, Clague JE, Horan MA, Lucas SB. New approach to risk determination: development of risk profile for new falls among community-dwelling older people by use of a Genetic Algorithm Neural Network (GANN). J Gerontol A Biol Sci Med Sci 2000; 55: M17-M21.

48. Campbell AJ, Borrie MJ, Spears GF. Risk factors for falls in a community-based prospective study of people 70 years and older. J Gerontol 1989; 44: M112-M117.

49. O'Loughlin JL, Robitaille Y, Boivin JF, Suissa S. Incidence of and risk factors for falls and injurious falls among the community-dwelling elderly. Am J Epidemiol 1993; 137: 342-354.

50. Lipsitz LA, Jonsson PV, Kelley, Koestner SS. Causes and correlated of recurrent falls in ambulatory frail elderly. J Gerontol 1991; 46: M114-M122.

51. Cumming RG, Klineberg RJ. Fall frequency and characteristics and the risk of hip fractures. J Am Geriatr Soc 1994; 42: 774-778.

52. Tinetti ME, Speechley M, Ginter SF. Risk factors for falls among elderly persons living in the community. $N$ Engl J Med 1988; 319: 1701-1707.

53. Nevitt MC, Cummings SR, Hudes ES. Risk factors for injurious falls: a prospective study. J Gerontol 1991; 46: M164-M170.

54. Speechley M, Tinetti M. Falls and injuries in frail and vigorous community elderly persons. J Am Geriatr Soc 1991; 39: 46-52.

55. Robbins AS, Rubenstein LZ, Josephson KR, Schulman BL, Osterweil D, Fine G. Predictors of falls among elderly people. Results of two population-based studies. Arch Intern Med 1989; 149: 1628-1633.

56. Faulkner KA, Cauley JA, Studenski SA, Landsittel DP, Cummings SR, Ensrud KE, et al. Lifestyle predicts falls independent of physical risk factors. Osteoporos Int 2009; 20: 2025-2034.

57. Delbaere K, Close JCT, Heim J, Sachdev PS, Brodaty H, Slavin MJ, et al. Multifactorial approach to understanding fall risk in older people. J Am Geriatr Soc 2010; 58: 1679-1685.

58. Moylan KC, Binder EF. Falls in older adults: risk assessment, management and prevention. Am J Med 2007; 120: 493-497.

59. Menz H, Hill KD. Podiatric involvement in multidisciplinary falls-prevention clinics in Australia. $J$ Am Podiatry Med Assoc 2007; 97: 377-384.

60. Kerber KA, Enrietto JA, Jacobson KM, Baloh RW. Disequilibrium in older people: a prospective study. Neurology 1998; 51: 574-580.

61. Campbell AJ, Reinken J, Allan BC, Martinez GS. Falls in old age: a study of frequency and related clinical factors. Age Ageing 1981; 10: 264-270.

62. Maki BE, Holliday PJ, Topper AK. A prospective study of postural balance and risk of falling in an ambulatory and independent elderly population. J Gerontol 1994; 49: M72-M84.

63. Campbell AJ, Spears GF. Fallers and non-fallers. Age Ageing 1990; 19: 345-346.

64. Urton MM. A community home inspection approach to preventing falls among the elderly. Public Health Rep 1991; 106: 192-195.

65. Ryynanen OP, Kivela SL, Honkanen R, Laippala P, Saano V. Medications and chronic diseases as risk factors for falling injuries in the elderly. Scand J Soc Med 1993; 21: 264-271. 
66. Kojima T, Akishita M, Nakamura T, Nomura K, Ogawa S, Iijima K, et al. Association of polypharmacy with fall risk among geriatric outpatients. Geriatr Gerontol Int 2011; 11: 438-444.

67. Prudham D, Evans JG. Factors associated with falls in the elderly: a community study. Age Ageing 1981; 10: 141-146.

68. Blake AJ, Morgan K, Bendall MJ, Dallosso H, Ebrahim SB, ArieTH, et al. Falls by elderly people at home: prevalence and associated factors. Age Ageing 1988; 17: 365-372.

69. Nelson R, Amin M. Falls in the elderly. Emerg Med Clin North Am 1990; 8: 309-325.

70. Lach HW, Reed AT, Arfken CL, Miller JP, Paige GD, Birge SJ, et al. Falls in the elderly: reliability of a classification system. J Am Geriatr Soc 1991; 39: 197-202.

71. Josephson KR, Fabacher DA, Rubenstein LZ. Home safety and fall prevention. Clin Geriatr Med 1991; 7: 707-731.

72. Sattin RW. Falls among older persons: a public health perspective. Annu Rev Public Health 1992; 13: 489508.

73. Tinetti ME, Baker DI, McAvay G, Claus EB, Garrett P, Gottschalk M, et al. A multifactorial intervention to reduce the risk of falling among elderly people living in the community. N Engl J Med 1994; 331: 821-827.

74. Graafmans WC, Ooms ME, Hofstee HMA, Bezemer PD, Bouter LM, Lips P. Falls in the elderly: A prospective study of risk factors and risk profiles. Am J Epidemiol 1996; 143: 1129-1136.

75. Kario K, Tobin JN, Wolfson LI, Whipple R, Derby CA, Singh D, et al. Lower standing systolic blood pressure as a predictor of falls in the elderly: a community-based prospective study. Am J Epidemiol 2001; 38: 246-252.

76. Lindqvist K, Timpka T, Schiep L. Evaluation of an inter-organizational prevention program against injuries among elderly. Public Health 2001; 115: 308-316.

77. Bell AJ, Talbot-Stern JK, Hennessy A. Characteristics and outcomes of older patients presenting to the emergency department after a fall: a retrospective analysis. Med J Aust 2000; 173: 179-182.

78. Luukinen H, Koski K, Laippala P, Kivela SL. Predictors for recurrent falls among the home-dwelling elderly. Scand J Prim Health Care 1995; 13: 294-299.

79. Brauer SG, Burns YR, Galley P. A prospective study of laboratory and clinical measures of postural stability to predict community-dwelling fallers. J Gerontol A BiolSci Med Sci 2000; 55: M469-M476.

80. Tromp AM, Pluijm SM, Smit JH, Deeg DJ, Bouter LM, Lips P. Fall-risk screening test: a prospective study on predictors for falls in community-dwelling elderly. J Clin Epidemiol 2001; 54: 837-844.

81. Flemming PJ. Utilization of a screening tool to identify homebound older adults at risk for falls: validity and reliability. Home Health Care Serv $Q$ 2006; 25: 1-26.

82. Andresen E, Wolinsky FD, Miller JP, Wilson M-M, Malmstrom TK, Miller DK. Cross-sectional and longitudinal risk factors for falls, fear of falling, and falls efficacy in a cohort of middle-aged African Americans. Gerontologist 2006; 46: 249-257.

83. Covinsky KE, Kahana E, Kahana B, Kercher K, Schumacher JG, Justice AC. History and mobility exam index to identify community-dwelling elderly persons at risk of falling. J Gerontol A Biol Sci Med Sci 2001; 56: M253-M259.

84. Tsai S, Yin J, Tung T, Shimada T. Falls efficacy among stroke survivors living in the community. Disabil Rehabil 2011; 33: 1785-1790.

85. Pickering RM, Grimbergen YAM, Rigney U, Ashburn A, Mazibrada G, Wood B, et al. A meta-analysis of six prospective studies of falling in Parkinson's disease. Mov Disord 2007; 22: 1892-1900.

86. Campbell AJ, Spears GF, Borrie MJ. Examination by logistic regression modelling of the variables which increase the relative risk of elderly women falling compared to elderly men. J Clin Epidemiol 1990; 43: 1415 1420.

87. Downton JH, Andrews K. Prevalence, characteristics and factors associated with falls among the elderly living at home. Aging (Milano) 1991; 3: 219-228.

88. Bergland A, Pettersen AM, Laake K. Falls reported among elderly Norwegian living at home. Phys Res Int 1998; 3: 164-174.

89. Perry BC. Falls among the elderly living in high-rise apartments. J Fam Pract 1982; 14: 1069-1073.

90. Svensson ML, Rundgren A, Landahl S. Falls in 84- to 85-year-old people living at home. Accid Anal Prev 1992; 24: 527-537.

91. Liu BA, Topper AK, Reeves RA, Gryfe C, Maki BE. Falls among older people: relationship to medication use and orthostatic hypotension. J Am Geriatr Soc 1995; 43: 1141-1145.

92. Reinsch S, MacRae P, Lachenbruch PA, Tobis JS. Why do healthy older adults fall? Behavioral and environmental risks. Phys Occup Ther Geriatr 1992; 11: 1-15.

93. Bergland A, Jarnlo GB. Laake K. Predictors of falls in the elderly by location. Aging Clin Exp Res 2003; 15: 43-50. 
94. Clark RD, Lord SR, Webster IW. Clinical parameters associated with falls in an elderly population. Gerontology 1993; 39: 117-123.

95. Lord SR, Ward JA. Age-associated differences in sensori-motor function and balance in community dwelling women. Age Ageing 1994; 23: 452-460.

96. World Health Organization. ICF: International Classification of Functioning, Disability and Health. Geneva: World Health Organization, 2001.

97. Vandervoort AA. Effects of ageing on human neuromuscular function: implications for exercise. Can J Sport Sci 1992; 17: 178-184.

98. Lord SR, Clark RD, Webster IW. Postural stability and associated physiological factors in a population of aged persons. J Gerontol 1991; 46: M69-M76.

99. Lord SR, Clark RD, Webster IW. Physiological factors associated with falls in an elderly population. $J$ Am Geriatr Soc 1991; 39: 1194-1200.

100. Sorock GS, Labiner DM. Peripheral neuromuscular dysfunction and falls in an elderly cohort. Am J Epidemiol 1992; 136: 584-591.

101. Richardson JK, Ching C, Hurvitz EA. The relationship between electromyographically documented peripheral neuropathy and falls. J Am Geriatr Soc 1992; 40: 1008-1012.

102. Richardson JK, Hurvitz EA. Peripheral neuropathy: A true risk factor for falls. J Gerontol A Biol Sci Med Sci 1995; 50: M211-M215.

103. Richardson JK, Ashton-Miller JA, Lee SG, Jacobs K. Moderate peripheral neuropathy impairs weight transfer and unipedal balance in the elderly. Arch Phys Med Rehabil 1996; 77: 1152-1160.

104. Richardson JK, Ashton-Miller JA. Peripheral neuropathy: an often overlooked cause of falls in the elderly. Postgrad Med 1996; 99: 161-172.

105. Hurley MV, Rees J, Newham DJ. Quadriceps function, proprioceptive acuity and functional performance in healthy young, middle-aged and elderly subjects. Age Ageing 1998; 27: 55-62.

106. Koski K, Luukinen H, Laippala P, Kivela S-L. Risk factors for major injurious falls among the home-dwelling elderly by functional abilities. A prospective population-based study. Gerontology 1998; 44: 232-238.

107. Lawson J, Fitzgerald J, Birchall J, Aldren CP, Kenny RA. Diagnosis of geriatric patients with severe dizziness. J Am Geriatr Soc 1999; 47: 12-17.

108. Era P, Heikkinen E. Postural sway during standing and unexpected disturbance of balance in random samples of men of different ages. J Gerontol 1985; 40: 287-295.

109. Era P, Schroll M, Ytting H, Gause-Nilsson I, Heikkinen E, Steen B. Postural balance and its sensory-motor correlates in 75-year-old men and women: a cross-national comparative study. J Gerontol A Biol Sci Med Sci 1996; 51: M53-63.

110. Lord SR, Lloyd DG, Li SK. Sensori-motor function, gait patterns and falls in community-dwelling women. Age Ageing 1996; 25: 292-299.

111. Anacker SL, Di Fabio RP, Horak FB. Influence of sensory inputs on standing balance in community-dwelling elders with a recent history of falling. Phys Ther 1992; 72: 575-584.

112. Kristinsdottir EK, Jarnlo GB, Magnusson M. Asymmetric vestibular function in the elderly might be significant contributor to hip fractures. Scand J Rehabil Med 2000; 32: 56-60.

113. Laake K, Jakaityte J. How is it with the "elderly wave". Tidsskr Nor Laegeforen 1997; 117: 3529-3531.

114. Di Fabio RP, Greany JF, Emasithi A, Wyman JF. Eye-head coordination during postural perturbation as a predictor of falls in community-dwelling elderly women. Arch Phys Med Rehabil 2002; 83: 942-951.

115. Kristinsdottir EK, Nordell E, Jarnlo GB, Tjäder A, Thorngren KG, Magnusson M. Observation of vestibular asymmetry in a majority of patients over 50 years with fall-related fractures wrist fractures. Acta Otolaryngol 2001; 121: 481-485.

116. Ivers RQ, Norton R, Cumming RG, Butler M, Campbell AJ. Visual impairment and risk of hip fracture. Am J Epidemiol 2000; 152: 633-639.

117. Ivers RQ, Cumming RG, Mitchell P, Attebo K. Visual impairment and falls in older adults: the Blue Mountains Eye Study. J Am Geriatr Soc 1998; 46: 58-64.

118. Lord SR, Clark RD, Webster IW. Visual acuity and contrast sensitivity in relation to falls in an elderly population. Age Ageing 1991; 20: 175-181.

119. Hirvela H, Koskela P, Laatikainen L. Visual acuity and contrast sensitivity in the elderly. Acta Ophthalmol Scand 1995; 73: 111-115.

120. Lord SR, Dayhew J. Visual risk factors for falls in older people. J Am Geriatr Soc 2001; 49: 508-515.

121. Fabre JM, Ellis R, Kosma M, Wood RH. Falls risk factors and a compendium of falls risk screening instruments. J Geriatr Phys Ther 2010; 33: 184-197.

122. McMurdo ME, Gaskell A. Dark adaptation and falls in the elderly. Gerontology 1991; 37: 221-224. 
123. Jack CI, Smith T, Neoh C, Lye M, McGalliard JN. Prevalence of low vision in elderly patients admitted to an acute geriatric unit in Liverpool: elderly people who fall are more likely to have low vision. Gerontology 1995; 41: 280-285.

124. Lord SR, Ward JA, Williams P, Anstey KJ. An epidemiological study of falls in older community-dwelling women: the Randwick falls and fractures study. Aust J Public Health 1993; 17: 240-245.

125. Glynn RJ, Seddon JM, Krug JH Jr, Sahagian CR, Chiavelli ME, Campion EW. Falls in elderly patients with glaucoma. Arch Ophthalmol 1991; 109: 205-210.

126. Lord SR, Sambrook PN, Gilbert C, Kelly PJ, Nguyen T, Webster IW, et al. Postural stability, falls and fractures in the elderly: results from the Dubbo Osteoporosis Epidemiology Study. MJA 1994; 160: 684-686.

127. Cho CY, Kamen G. Detecting balance deficits in frequent fallers using clinical and quantitative evaluation tools. J Am Geriatr Soc 1998; 46: 426-430.

128. Robbins AS, Rubenstein LZ, Josephson KR, Schulman BL, Osterweil D, Fine G. Predictors of falls among elderly people. Results of two population-based studies. Arch Intern Med 1989; 149: 1628-1633.

129. Chan BKS, Marshall LM, Winters KM, Faulkner KA, Schwartz AV, Orwoll ES. Incident fall risk and physical activity and physical performance among older men. Am J Epidemiol 2007; 165: 696-703.

130. Stel VS, Smit JH, Pluijm SMF, Lips P. Balance and mobility performance as treatable risk factors for recurrent falling in older persons. J Clin Epidemiol 2003; 56: 659-668.

131. DeMott TK, Rickardson JK, Thies SB, Ashton-Miller JA. Falls and gait characteristics among older persons with peripheral neuropathy. Am J Phys Med Rehabil 2007; 86: 125-132.

132. Beninato M, Portney LG, Sullivan PE. Using the International Classification of Functioning, Disability and Health as a framework to examine the association between falls and clinical assessment tools in people with stroke. Phys Ther 2009; 89: 816-825.

133. CzernuszenkoA, Czlonkowska A. Risk factors for falls in stroke patients during inpatient rehabilitation. Clin Rehabil 2009; 23: 176-188.

134. Grundstrom AC, Guse CE, Layde PM. Risk factors for falls and fall-related injuries in adults 85 years of age and older. Arch Geront Geriatr 2012; 54: 421-428.

135. Simpson LA, Miller WC, Eng JJ. Effect of stroke on fall rate, location and predictors: a prospective comparison of older adults with and without stroke. PLoS One 2011; 6: e19431.

136. Schmid AA, Kapoor JR, Dallas MB, Dawn M. Association between stroke severity and fall risk among stroke patients. Neuroepidemiology 2010; 34: 158-162.

137. Carey BJ, Potter JF. Cardiovascular causes of falls. Age Ageing 2001; 30 (Suppl 4): 19-24.

138. Menz HB, Lord SR. Foot problems, functional impairment, and falls in older people. J Am Podiatr Med Assoc 1999; 89: 458-467.

139. Moreland JD, Richardson JA, Goldsmith CH, Clase CM. Muscle weakness and falls in older adults: a systematic review and metaanalysis. J Am Geriatr Soc 2004; 52: 1121-1129.

140. Wright SL, Kay RE, Avery ET, Giordani B, Alexander NB. The impact of depression on dual task among patients with high fall risk. J Geriatr Psychiatry Neurol 2011; 24: 142-150.

141. Alexander NB, Mollo JM, Giordani B, Ashton-Miller JA, Schultz AB, Grunawalt JA, et al. Maintenance of balance, gait patterns, and obstacle clearance in Alzheimer's disease. Neurology 1995; 45: 908-914.

142. Lord SR, Clark RD. Simple physiological and clinical tests for the accurate prediction of falling in older people. Gerontology 1996; 42: 199-203.

143. Fried AV, Cwikel J, Ring H, Galinsky D. ELGAM-extra-laboratory gait assessment method: identification of risk factors for falls among the elderly at home. Int Disabil Stud 1990; 12: 161-164.

144. Brown LA, Shumway-Cook A, Woollacott MH. Attentional demands and postural recovery: the effects of aging. J Gerontol A Biol Sci Med Sci 1999; 54: M165-M171.

145. Marsh AP, Geel SE. The effect of age on the attentional demands of postural control. Gait Posture 2000; 12: 105-113.

146. Shumway-Cook A, Woollacott M. Attentional demands and postural control: the effect of sensory context. $J$ Gerontol A Biol Sci Med Sci 2000; 55: M10-M16.

147. Muir SW, Gopaul K, Montero Odasso MM. The role of cognitive impairment in fall risk among older adults: a systematic review and meta-analysis. Age Ageing 2012; 41: 299-308.

148. Woolley SM, Czaja SJ, Drury CG. An assessment of falls in elderly men and women. J Gerontol A Biol Sci Med Sci 1997; 52: M80-M87.

149. Holtzer R, Friedman R, Lipton RB, Katz M, Xuc X, Verghese J. The relationship between specific cognitive functions and falls in aging. Neuropsychology 2007; 21: 540-548.

150. Arfken CL, Lach HW, Birge SJ, Miller JP. The prevalence and correlates of fear of falling in elderly persons living in the community. Am J Public Health 1994; 84: 565-570.

151. Leipzig RM, Cumming RG, Tinetti ME. Drugs and falls in older people: a systematic review and metaanalysis: I. Psychotropic drugs. J Am Geriatr Soc 1999; 47: 30-39. 
152. Leipzig RM, Cumming RG, Tinetti ME. Drugs and falls in older people: A systematic review and metaanalysis: II. Cardiac and analgesic drugs. J Am Geriatr Soc 1999; 47: 40-50.

153. Cumming RG. Epidemiology of medication-related falls and fractures in the elderly. Drugs Aging 1998; 12: 43-53.

154. Ziere G, Dieleman JP, Hofman A, Pols HAP, van der Cammen TJ, Stricker BH. Polypharmacy and falls in the middle age and elderly population. Br J Clin Pharmacol 2005; 61: 218-223.

155. Hartikainen S, Lönnroos E, Louhivuon K. Medication as a risk factor for falls: Critical systematic review. Gerontology 2007; 62A: 1172-1181.

156. French DD, Campbell R, Spehar A, Cunningham F, Bulat T, Luther S. Drugs and falls in communitydwelling older people: a national veterans study. Clin Ther 2006; 28: 619-630.

157. Gregg EW, Pereira MA, Caspersen CJ. Physical activity, falls, and fractures among older adults: a review of the epidemiologic evidence. J Am Geriatr Soc 2000; 48: 883-893.

158. Jørstad-Stein EC, Hauer K, Becker C, Bonnefoy M, Nakash RA, Skelton DA, et al. Suitability of physical activity questionnaires for older adults in fall-prevention trials: a systematic review. J Aging Phys Act 2005; 13: 461-481.

159. Rawsky E. Review of the literature on falls among the elderly. Image J Nurs Sch 1998; 30: 47-52.

160. Cox E, Tseng DS, Powell I. Trends in falls, poisoning, drowning, and burns Wisconsin: 1986-1996. Wis Med $J$ 2001; 100: 39-42.

161. Elliott S, Painter J, Hudson S. Living alone and fall risk factors in community-dwelling middle age and older adults. J Community Health 2009; 34: 301-310.

162. Buatois S, Perret-Guillaume C, Gueguen R, Miget P, Vançon G, Perrin P, et al. A simple clinical scale to stratify risk of recurrent falls in community-dwelling adults aged 65 years and older. Phys Ther 2010; 90: 550-560.

163. Pynoos J, Steinman BA, Nguyen AQ. Environmental assessment and modification as fall-prevention strategies for older adults. Clin Geriatr Med 2010; 26: 633-44.

164. Bath PA, Morgan K. Differential risk factor profiles for indoor and outdoor falls in older people living at home in Nottingham, UK. Eur J Epidemiol 1999; 15: 65-73.

165. Weinberg LE, Strain LA. Community-dwelling older adults' attributions about falls. Arch Phys Med Rehabil 1995; 76: 955-960.

166. Wenjun Li, Keegan THM, Sternfeld B, Sidney S, Quesenberry CP Jr, Kelsey JL. Outdoor falls among middleaged and older adults: A neglected public problem. Am J Public Health 2006; 96: 1192-1200.

167. van Weel C, Vermeulen H, van den Bosch W. Falls, a community care perspective. Lancet 1995; 345: 15491551 .

168. Studenski S, Duncan PW, Chandler J, Samsa G, Prescott B, Hogue C, et al. Predicting falls: The role of mobility and nonphysical factors. J Am Geriatr Soc1994; 42: 297-302.

169. Dresner-Pollak R, Ginsberg G, Cohen A, Stessman J. Characteristics of falls in 70 year olds in Jerusalem. Isr J Med Sci 1996; 32: 625-628.

170. Scout V, Votova K, Scanlan A, Close J. Multifactorial and functional mobility assessment tools for fall risk among older adults in community, home-support, long-term and acute care settings. Age Ageing 2007; 36: 130-139.

171. Close J, Lord S, Menz HB, Sherrington C. What is the role of falls. Best Pract Res Clin Rheumatol 2005; 19: 913-935.

172. Bongue B, Dupré C, Beauchet O, RossatA, Fantino B, Colvez A. A screening tool with five risk factors was developed for fall-risk prediction in community-dwelling elderly. J Clin Epidemiol 2011; 64: 1152-1160.

173. Renfro MO, Fehrer S, Multifactorial screening for fall risk in community-dwelling older adults in the primary care office: Development of the Fall Risk Assessment \& Screening Tool. J Geriatr Phys Ther 2011; 34: 174183.

174. American Geriatrics Society, British Geriatrics Society. AGS/BGS Clinical Practice Guideline: Prevention of Falls in Older Persons (2010). Assessed at http://www.americangeriatrics.org/health_care_professionals/ clinical_practice/clinical_guidelines_recommendations/2010/, on 25 May 2012.

175. Perell KL, Nelson A, Goldman RL, Luther SL, Prieto-Lewis N, Rubenstein LZ. Falls risk assessment measure: an analytical review. Gerontology 2001; 56A: M761-M766.

176. Lajoie Y, Gallagher SP. Predicting falls within the elderly community: comparison of postural sway, reaction time, the Berg balance scale and the Activities-specific Balance Confidence scale for comparing fallers and non-fallers. Arch Gerontol Geriatr 2004; 38: 11-26.

177. Jarnlo G-B. Functional balance tests related to falls among elderly people living in the community. Eur $J$ Geriatrics 2003; 5: 7-14.

178. Neuls PD, Tammie CL, Van Heuklon NC, Proctor JE, Kilker BJ, Bieber ME, et al. Usefulness of the Berg Balance Scale to predict falls in the elderly. J Geriatric Physical Therapy 2011; 34: 3-10. 
179. Maki BE. Gait changes in older adults: Predictors of falls or indicators of fear? J Am Geriatr Soc 1997; 45: 313-320.

180. Bergland A, Jarnlo G-B, Laake K. Validity of an index of self-reported walking for balance and falls in elderly women. Adv Physiother 2002; 4: 65-73.

181. Montero-Odasso M, Schapira M, Soriano ER, Varela M, Kaplan R, Camera LA, et al. Gait velocity as a single predictor of adverse events in healthy seniors aged 75 years and older. J Gerontol A Biol Sci Med Sci 2005; 60A: 1304-1309.

182. Hausdorff JM, Rios DA, Edelberg HK. Gait variability and fall risk in community-living older adults: a 1year prospective study. Arch Phys Med Rehabil 2001; 82: 1050-1056.

183. Piirtola M, Era P. Force platform measurements as predictors of falls among older people. A review. Gerontology 2006; 52: 1-16.

184. Buatois S, Gueguen R, Gauchard GC, Benetos A, Perrin PP. Posturography and risk of recurrent falls in healthy non-institutionalized persons aged over 65. Gerontology 2006; 52: 345-352.

185. Hale WA, Delaney MJ, McGaghie WC. Characteristics and predictors of falls in elderly patients. J Fam Pract 1992; 34: 577-581.

186. Hill K, Schwarz J, Flicker L, Carroll S. Falls among healthy, community-dwelling, older women: a prospective study of frequency, circumstances, consequences and prediction accuracy. Aust $N$ Z J Public Health 1999; 23: 41-48.

187. Altman DG. Systematic reviews of evaluations of prognostic variables. BMJ 2001; 323: 224-228.

188. Lijmer JG, Mol BW, Heisterkamp S, Bonsel GJ, Prins MH, van der Meulen JH, et al. Empirical evidence of design-related bias in studies of diagnostic tests. JAMA 1999; 282: 1061-1066. 